\title{
Correlação entre diversidades genéticas em genótipos de milho, obtidas em diferentes combinações de ambientes
}

\section{Correlation between environments in genetic divergence in corn genotypes in late planting}

1,* (D) Weder Ferreira dos SANTOS, 2, (DD Flávio Sérgio AFFÉRRI, 1, (iD) Joênes Mucci PELÚZIO, 1, (iD Layanni Ferreira SODRÉ, 1, (iD Raimundo Wagner de Souza AGUIAR e ${ }^{1,(D)}$ Lucas Carneiro MACIEL

1 Universidade Federal do Tocantins. Campus Universitário de Gurupi, Rua Badejós, S/N Zona Rural. CEP 77402-970 - Gurupi, TO Brasil.

2 Universidade Federal de São Carlos. Campus Lagoa do Sino, Rodovia Lauri Simões de Barros, km 12 - SP-189. CEP $18290-000$ Aracaçú, Buri, SP - Brasil.

*Autor para correspondência: eng.agricola.weder@gmail.com

\section{RESUMOI}

OPPEN ACESS

\section{Informações adicionais}

Recebido em: 19/12/2016

Aceito em: 05/03/2017

Publicado em: 07/08/2017

Editor:

Vinicius Batista Campos Instituto Federal do Amapá Macapá, AP.

Vinicius.campos@ifap.edu.br

\section{Revisão às cegas por pares}

Processos de revisão

Prot. 1322017R01 (Brasil)

Prot. 1322017R02 (Brasil)

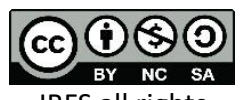

JBFS all rights

Copyright: @ 2017
O presente trabalho tem como objetivo estudar a correlação entre diferentes ambientes da diversidade genética em genótipos de milho, no município de Palmas, Estado do Tocantins, em plantio tardio. Os ensaios foram distribuídos em duas épocas de plantio (21/01/2014 e 19/02/2014). Em cada época, os ensaios foram realizados sob condições de alto nitrogênio $(N)$, médio $N$ e baixo $N$, em adubação de cobertura, proporcionando 6 ambientes, para cada época. $O$ delineamento experimental utilizado, em cada ensaio, foi o de blocos casualizados com três repetições e 12 tratamentos (genótipos) de milho. Foram utilizadas 16 características agronômicas. Foi realizado estudo da divergência genética para cada um dos ensaios, para todos os ensaios em conjunto e para diferentes combinações dos mesmos. Foram detectados efeitos significativos para as correlações em $30 \%$ dos pares. No AMB 1 apresentou correlação positiva e significativa para a grande maioria das combinações, o que, demonstrando possibilidade na redução do número de experimentos para estudo da diversidade. E a não significância da correlação entre as épocas 1 ( $A M B 2$ ) e época 2 (AMB 3), exemplifica a necessidade de condução de ensaios em épocas distintas.

Palavras-chaves: Dissimilaridade genética. Tocantins. Zea mays

\section{ABSTRACT}

This study aimed to study the correlation between different environments of genetic diversity in corn genotypes in the city of Palmas, Tocantins, in late planting. The tests were divided into two planting dates (01.21.2014 and 02.19.2014). In each time the tests were performed under conditions of high nitrogen $(\mathrm{N})$, mean $\mathrm{N}$ and low $\mathrm{N}$ in topdressing, yielding 6 environments. The experimental design used in each test was a randomized complete block design with three replications and 12 treatments (genotypes) of corn coming from the. Sixteen agronomic traits were used. Was conducted study of genetic diversity for each test, all tests together and combinations thereof. Significant effects were detected for the correlations in $30 \%$ of the pairs. In AMB 1, there was a positive and significant correlation for the great majority of combinations, which showed a possibility in reducing the number of experiments to study diversity. And the nonsignificance of the correlation between periods 1 (AMB 2) and season 2 (AMB 3), exemplifies the need to conduct trials at different times.

Keywords: Genetic dissimilarity. Tocantins. Zea mays. 


\section{INTRODUÇÃO}

O Brasil é o terceiro maior produtor mundial de milho e, assim como acontece mundialmente, no Brasil o milho é uma das espécies agrícolas de maior importância, tanto com relação à área cultivada quanto à produção (BORÉM et al., 2015). Dentre as espécies produtoras de grãos, a cultura do milho só é superada pelo complexo da soja em termos de áreas cultivada (CONAB, 2016), mas prevalece como a espécie com maior volume de produção tendo papel indiscutível na economia brasileira.

A baixa produtividade em algumas regiões brasileira de acordo a Conab (2016), pode ser devido a fatores climáticos específicos, mas o que mais contribui para isso é a falta da adoção de genótipos melhorados ou insuficiência de sementes melhoradas e adaptadas às condições de estresses abióticos, ou pelas práticas agronômicas empregadas (BORÉM et al., 2015).

Pode-se usar o conhecimento de correlações entre as características de importância econômica, uma vez que fornecer informações que auxiliem no processo de seleção de genótipos superiores (CABRAL et al., 2016).

As correlações genotípicas positivas indicam que a seleção objetivando ganho em uma característica provocará o mesmo efeito na outra (CABRAL et al., 2016; ENTRINGER et al., 2014). O ambiente torna-se causa de correlações quando duas características são influenciadas pelas mesmas variações de condições ambientais; em que valores negativos dessa correlação, evidenciam que o ambiente favoreceu uma característica em detrimento da outra, e valores positivos, que ambas foram beneficiadas ou prejudicadas pelas mesmas causas de variações ambientais (FALCONER, 1981).

A correlação é analisada quanto à magnitude e natureza da relação presente entre dois caracteres. Pode-se obter correlações de natureza negativa ou positiva, quando um par de caracteres apresenta relação inversamente proporcional ou diretamente proporcional, respectivamente. A magnitude, por sua vez, pode variar de -1 a +1 , de modo que quanto mais próximo a 1 for o valor obtido, mais forte será a correlação entre os dois caracteres (CRUZ et al., 2012).

Cruz et al. (2012) ressaltam a importância de se distinguir e quantificar o grau de associação genética e ambiental entre as características avaliadas, uma vez que as causas genéticas de correlação possuem natureza herdável e podem auxiliar na orientação de programas de melhoramento.

O objetivo da diversidade é proporcionar possibilidade de obtenção de novos genótipos (melhoramento), mas conhecer a diversidade dos genótipos podem ter influência do ambiente, Cruz et al. (2011) e Silva et al. (2015), indica o uso de um maior número de ambientes para o estudo da divergência genética, mais precisa poderá ser a informação.

Atualmente são poucos os estudos sobre a divergência genética em doses de adubos nitrogenado (Santos et al. 2014; Silva et al., 2015; Santos et al., 2015) e épocas de plantio (DOTTO et al., 2010; SIMON et al., 2012). Porém estes estudos não relatam as correlações entre ambientes quanto à diversidade genética.

Diante do exposto, o presente trabalho foi realizado com o intuito de identificar as correlações entre as diversidades obtidas nas diferentes combinações dos ambientes, em genótipos de milho na região central do Estado do Tocantins.

\section{MATERIAL E MÉTODOS}

No ano de 2014, foram realizados seis ensaios de genótipos de milho, distribuídos em duas épocas de semeadura (21/01 e 19/02), no Centro Agrotecnológico da Universidade Federal do Tocantins (UFT), Campus de Palmas (220 
m de altitude, 1045' de latitude Sul e 47014' de latitude Oeste), em solo do tipo Latossolo Vermelho Amarelo distrófico. Em cada época, os ensaios foram instalados sob condições de alto nitrogênio (alto N) $\left(140 \mathrm{~kg} \mathrm{ha}^{-1}\right)$, Médio N $\left(80 \mathrm{~kg} \mathrm{ha}^{-1}\right)$ e Baixo N $\left(0 \mathrm{~kg} \mathrm{ha}^{-1}\right)$ em cobertura.

O delineamento experimental utilizado, em cada ensaio, foi em blocos casualizados com 12 tratamentos e três repetições. Os tratamentos foram constituídos por 12 genótipos de polinização aberta, sendo denominadas: GEN 1, GEN 2, GEN 3, GEN 4, GEN 5, GEN 6, GEN 7, GEN 8, GEN 9, GEN 10, GEN 11 e GEN 12.

A parcela experimental foi representada por quatro linhas de cinco metros lineares, espaçadas por $0,90 \mathrm{~m}$ entre linhas. $\mathrm{Na}$ colheita, foram utilizadas as duas linhas centrais de cada fileira, descartando-se $0,50 \mathrm{~m}$ das extremidades das fileiras.

Foi utilizado o sistema de preparo de solo tipo convencional, com uma gradagem seguida do nivelamento da área. A adubação de pré-semeadura foi realizada manualmente, utilizando $300 \mathrm{~kg} \mathrm{ha}^{-1}$ de NPK de $5-25-15+0,5 \% \mathrm{Zn}$, para todos os ensaios. A semeadura foi realizada com o intuito de se obter 55 mil plantas ha-1.

A adubação em cobertura foi realizada apenas com $N$ no estádio $V 6$, tendo como fonte de $\mathrm{N}$ a uréia. A dosagem foi de 0,80 e $140 \mathrm{~kg} \mathrm{ha}^{-1}$ de $\mathrm{N}$, proporcionando ambientes de Baixo, Médio e Alto N, respectivamente.

Os tratos culturais, como o controle fitossanitário contra doenças, pragas e plantas daninhas foram realizados de acordo com as recomendações técnicas da cultura.

Em cada parcela, foram avaliadas as seguintes características: 1) altura de plantas (AP); 2) altura de espiga (AE); 3) número de folhas totais na planta (NF); 4) número de folhas acima da espiga principal (NFAE); 5) peso da espiga com palha (PECP); 6) peso da espiga sem palha (PESP); 7) diâmetro da espiga (DE); 8) comprimento de espigas (CE); 9) número de fileiras de grãos (NFE); 10) número de grãos por fileira (NGF); 11) diâmetro do sabugo (DS); 12) umidade (UMI); 13) largura do grão (LG); 14$)$ comprimento do grão (CG); 15$)$ altura do grão (AG); 16) peso de grãos por planta (PGPL).

Foi realizado estudo da divergência genética para cada um dos ensaios, para todos os ensaios em conjunto e para as combinações dos mesmos, quais sejam: Divergência genética nos seguintes ambientes formados AMB 1: Distâncias com todos os ensaios em conjunto; $A M B$ 2: primeira época de semeadura com as três doses; $A M B$ 3: segunda época de semeadura com as três doses; $A M B$ 4: ensaios em baixo $N$ na duas épocas de semeadura; $A M B$ 5: baixo $N$ na primeira época; $A M B$ 6: baixo $N$ na segunda época; $A M B$ 7: médio $N$ na duas épocas de semeadura; $A M B$ 8: médio $N$ na primeira época; $A M B$ 9: médio $N$ na segunda época; $A M B$ 10: alto $N$ na duas épocas de semeadura; $A M B$ 11: alto $N$ na primeira época; $A M B$ 12: alto $N$ na segunda época.

A partir deste estudo foram correlacionados os ambientes pelos valores obtidos nas distâncias generalizada de Mahalanobis $\left(D_{2}\right)$ para cada um dos pares de genótipos, através da correlação Pearson, sendo utilizado o teste "t" ao nível de $5 \%$ significância.

As análises foram realizadas utilizando o programa Computacional Genes (Cruz, 2007).

\section{RESULTADOS E DISCUSSÃO}

O resultado das correlações para as medidas de dissimilaridade de Mahalanobilis, entre os pares de ambientes, encontram-se na Tabela 1. As correlações variaram de 0,05 (AMB9 e AMB11) a 0,94 (AMB3 a AMB6), sendo detectados efeitos significativos para as correlações em $30 \%$ dos pares, de um total de 66 . A seleção de determinado ambiente pode ter sua importância aumentada conforme se obtém 
conhecimento a respeito das correlações com o as distâncias de Mahalanobilis obtidas com um maior número de ambientes analisados conjuntamente (CARPENTIERI-PÍPOLO et al., 2012).

Tabela 1. Estimativas dos coeficientes de correlações fenotípicas, entre as dozes distâncias estudadas, nos ensaios realizados no ano agrícola de 2014, em Palmas-TO.

Table 1. Estimates of the phenotypic correlation coefficients, between the twelve distances studied, in the tests carried out in the agricultural year of 2014, in Palmas-TO.

\begin{tabular}{|c|c|c|c|c|c|c|c|c|c|c|c|c|}
\hline & Distâncias & 1 & 2 & 3 & 4 & 5 & 6 & 7 & 8 & 9 & 10 & 11 \\
\hline 2 & 1a época & $0,85^{*}$ & & & & & & & & & & \\
\hline 3 & 2a época & $0,67^{*}$ & 0,41 & & & & & & & & & \\
\hline 4 & Baixo $N, 1^{a}$ e 2 a épocas & $0,72^{*}$ & $0,68^{*}$ & 0,60 & & & & & & & & \\
\hline 5 & Baixo N, 1a época & 0,56 & $0,72^{*}$ & 0,41 & $0,78^{*}$ & & & & & & & \\
\hline 6 & Baixo N, 2a época & $0,65^{*}$ & 0,43 & $0,94 *$ & $0,66^{*}$ & 0,48 & & & & & & \\
\hline 7 & Médio $N, 1$ e e $2^{\mathrm{a}}$ épocas & $0,76^{*}$ & $0,76^{*}$ & 0,52 & 0,52 & 0,62 & 0,58 & & & & & \\
\hline 8 & Médio N, 1a. Época & 0,42 & 0,24 & $0,84^{*}$ & 0,49 & 0,32 & 0,48 & 0,33 & & & & \\
\hline 9 & Médio N 2ạ. Época & 0,58 & 0,38 & 0,42 & 0,27 & 0,25 & 0,37 & 0,35 & 0,15 & & & \\
\hline 10 & Alto $\mathrm{N}, 1$ e $2^{\mathrm{a}}$ épocas & $0,68^{*}$ & 0,42 & 0,60 & 0,36 & 0,23 & 0,58 & 0,37 & 0,42 & $0,86^{*}$ & & \\
\hline 11 & Alto N, 1a. Época & 0,48 & 0,60 & 0,25 & 0,38 & 0,45 & 0,29 & $0,74^{*}$ & 0,16 & 0,05 & 0,33 & \\
\hline 12 & Alto N, 2a época & $0,66^{*}$ & 0,41 & $0,90^{*}$ & 0,56 & 0,34 & $0,87^{*}$ & 0,45 & $0,72^{*}$ & 0,43 & $0,67^{*}$ & 0,19 \\
\hline
\end{tabular}

*Significativo a 0,05 pelo teste t. Divergência genética AMB1: todos os ensaios em conjunto (divergência geral); AMB 2: primeira época de semeadura; $A M B$ 3: segunda época de semeadura; $A M B$ 4: baixo $N$ na duas épocas de semeadura; $A M B$ 5: baixo $N$ na primeira época; $A M B$ 6: baixo $N$ na segunda época; $A M B$ 7: médio $N$ na duas épocas de semeadura; $A M B$ 8: médio $N$ na primeira época; $A M B$ 9: médio $N$ na segunda época; $A M B$ 10: alto $N$ na duas épocas de semeadura; $A M B$ 11: alto $N$ na primeira época; $A M B$ 12: alto $N$ na segunda época.

As correlações positivas e entre AMB 1 apresentou correlação positiva e significativa para a grande maioria das combinações, com exceção dos ambientes envolvendo a primeira época de semeadura AMB 5 (Baixo N), AMB 8 (Médio N) e AMB 11 (Alto N, 1a. época). Isso aconteceu devido as distâncias das divergências genéticas entre os genótipos variar de um ambiente para outro (Silva et al., 2015).

As correlações positivas e significativas com o AMB 1 (geral -> épocas 1 e 2) com os AMB 2 (primeira época) $(0,85)$ e AMB 3 (segunda época) $(0,67)$ e não significativas com a primeira época de semeadura para os ambientes AMB 5 (Baixo N), AMB 8 (Médio N) e AMB 11 (Alto $N$ ), aliada à não significância da correlação entre as épocas 1 ( $A M B$ 2) e época 2 ( $A M B 3$ ), retrata a necessidade de condução de ensaios em épocas distintas, em virtude da existência da influência do ambiente e das interações genótipos por ambientes na expressão diferencial dos genes, que pode dificultar o processo de seleção. Este fato ocorreu devido a mudança de posicionamento das divergências genéticas nos diferentes ambientes dificultando a recomendação dos mesmos em ampla faixa de adaptação nas distâncias genéticas estudadas (Pacheco et al., 2008).

Correlações positivas e não significativas foram observadas entre os ambientes de Baixo $N$ (AMB 5), AMB 8 (Médio N) e AMB 11 (Alto N), apenas para a primeira época, entre os ambientes (Baixo N (AMB 6), AMB 9 (Médio N) e AMB 12 (Alto N), apenas na segunda época, e entre os ambientes $A M B$, AMB 7 e AMB 10, em conjunto para ambas as épocas, indicam o efeito do $\mathrm{N}$ no comportamento diferencial dos genótipos. Santos et al. (2015) em seu trabalho com teor de óleo, revela similaridade para a divergência genética entre os genótipos para estes ambientes 
(AMB 5, AMB 6, AMB 8, AMB 9, AMB 11 e AMB 12), indicando, provavelmente, que os efeitos ambientais oriundos de duas épocas distintas de semeaduras não promoveram efeitos nos ambientes.

\section{CONCLUSÃO}

Foram detectados efeitos significativos para as correlações em $30 \%$ dos pares.

O AMB 1 apresentou correlação positiva e significativa para a grande maioria das combinações, o que, demonstrando possibilidade na redução do número de experimentos para estudo da diversidade.

E a não significância da correlação entre as épocas 1 ( $A M B$ 2) e época 2 (AMB 3), exemplifica a necessidade de condução de ensaios em épocas distintas.

\section{CONTIRBUIÇÃO DOS AUTORES}

Planejamento e condução experimental: Os autores WFS, FSA, JMP e LFS; Formatação e revisão final do artigo: autores RWSA e LCM.

\section{CONFLITO DE INTERESSE}

Os autores declararam que não há conflito de interesse.

\section{FINANCIAMENTO}

Os autores afirmaram que não receberam ajuda financeira para o desenvolvimento do trabalho.

\section{REFERÊNCIAS BIBLIOGRÁFICAS}

BORÉM, A.; GALVÃO, J.C.C.; PIMENTEL, M.A. Milho: do plantio à colheita. Viçosa: UFV, 2015. 351p.

CABRAL, P.D.S.; AMARAL JÚNIOR, A.T.; FREITAS, I.L.J.; RIBEIRO, R.M.; SILVA, T.R.C. Relação causa e efeito de caracteres quantitativos sobre a capacidade de expansão do grão em milho-pipoca. Revista Ciência Agronômica, v.47, n.1, p.108-117, 2016. DOI: 10.5935/1806-6690.20160013

CARPENTIERI-PÍPOLO, V.; TAKAHASHI, H.W.; ENDO, R.M.; PETEK, M.R.; SEIFERT, A.L. Correlações entre caracteres quantitativos em milho pipoca, Horticultura Brasileira, v.20, n.4, p. 551-554, 2012. DOI:10.1590/S0102-05362002000400008

CONAB - Companhia Nacional de Abastecimento. Acompanhamento da safra brasileira de grãos: Monitoramento agrícola da Safra 2015/16. Brasília: CONAB, v.9, n.3, 2016. 174p.

CRUZ, C.D. Programa Genes: Aplicativo computacional em genética e estatística, Viçosa: UFV, 2007. $442 \mathrm{p}$.

CRUZ, C.D.; FERREIRA, F.M.; PESSONI, L.A. Biometria aplicada ao estudo da diversidade genética. Suprema: Visconde do Rio Branco, 2011. 620p.

CRUZ, C.D.; REGAZZI, A.J.; CARNEIRO, P.C.S. Modelos biométricos aplicados ao melhoramento genético. 4a ed Viçosa: UFV, 2012. 514p.

DOTTO, M.A.; AFFÉRRI, F.S.; PELÚZIO, J.M.; MELO, A.V.; CARVALHO, E.V. Divergência genética entre cultivares comerciais de milho em baixas altitudes no Tocantins, safra 2007/2008. Revista Ciência Agronômica, v.41, n.4, p.630-637, 2010. 
ENTRINGER, G.C.; SANTOS, P.H.A.; VETTORAZZI, J.C.F.; CUNHA, K.S.; PEREIRA, M.G. Correlação e análise de trilha para componentes de produção de milho superdoce. Revista Ceres, v.61, n.3, p.356-361, 2014. DOI: 10.1590/S0034-737X2014000300009

FALCONER, D.S. Introduction to quantitative genetics. 3o ed. New York: Longman, 1981. 489p.

PACHECO, L.P.; PIRES, F.R.; MONTEIRO, F.P.; PROCOPIO, S. O.; ASSIS, R.L.; CARMO, M.L.; PETTER, F.A. Desempenho de plantas de cobertura em sobressemeadura na cultura da soja. Pesquisa Agropecuária Brasileira, v.43, p.815-823, 2008.

SANTOS, W.F.; AFFÉRRI, F.S.; PELÚZIO, J.M. Eficiência ao uso do nitrogênio e biodiversidade em genótipos de milho para teor de óleo. Enciclopédia Biosfera, v.11, n.21, p.2916-2925, 2015.

SANTOS, W.F.; PELÚZIO, J.M.; AFFÉRRI, F.S.; SODRÉ, L.F.; SANTOS, D.S.; FARIAS, T.C.M. Variabilidade genética e eficiência de uso do nitrogênio em genótipos de milho para teor de óleo. Revista Ciência Agrárias, v.57, n.3, p.312-317, 2014. DOI:10.4322/rca.ao1358

SILVA, K.C.L.; SILVA, K.P.; CARVALHO, E.V.; ROTILI, E.A.; AFFÉRRI, F.S.; PELÚZIO, J.M. Divergência genética de genótipos de milho com e sem adubação nitrogenada em cobertura. Revista Agro@mbiente On-line, v.9, n.2, p.102-110, 2015. DOI:10.18227/1982-8470ragro.v9i2.2142

SIMON, G.A.; KAMADA, T.; MOITEIRO, M. Divergência genética em milho de primeira e segunda safra. Semina, v.33, n.2, p.449-458, 2012. DOI: 10.5433/1679-0359.2012v33n2p449 